\title{
Primeros meses de 1854, según Manuel Díez de Bonilla
}

José Ma. Muriá

Manuel Diez de Bonilla fue de lo mejor y más granado de los conservadores mexicanos durante los primeros cincuenta ânos de vida independiente, habiendo sido incluso jefe de su partido político. Más ligado a los intereses del centro de México no podría estar: nació en la capital durante el año de 1800 y, 64 años después, cuando el imperio de Maximiliano empezó a erigirse, para su gran satisfacción con un empuje que se antojaba incontrovertible. murió en la misma ciudad capital donde tenía asentados los reales que lo abastecian de no poco dinero.

Era criollo de vastísimos conocimientos, especialmente en materia de ciencias naturales. La gran fama que tenía su vocación por el orden antiguo no era menor a la de su nutrida y selecta biblioteca, que fue saqueada junto con su casa y gabinete de física por unos amotinados, en agosto de 1855 .

Díez de Bonilla desempeñó no pocas funciones públicas a lo largo de su vida: vicepresidente del Consejo de Estado, secretario perpetuo de la Academia de San Carlos y presidente de sus Juntas, ministro del Supremo Tribunal de Justicia y secretario de Gobernación, pero fue en el ámbito de las relaciones exteriores donde mayor empeño puso.

Fue el primer diplomático mexicano en Centroamérica a partír de noviembre de 1831 , ocho años después de establecida la República de ese nombre, habiendo sido nombrado también para representar a México en Colombia.' Era la época en que Lucas Alamán se ocupaba de la cartera de Relaciones y propondría el llamado "Pacto de Familia": "la unión de todas las Repúblicas formadas de lo que antes fueron colonias españolas, para que procedan de acuerdo en todo lo que pueda llamarse de interés común".2

El "Pacto" no llegó a establecerse, pero en cambio Diez de Bonilla. antes de retirarse en marzo de 1833, logró abrir anchos canales de comunicación con Guatemala, el país de América que, según las instrucciones que le dio el propio Alamán, era el que más interesaba a México."

Méritos en campaña y definida ideología hicieron de Díez de Bonilla el sucesor de José María Gutiérrez Estrada como secretario de Relaciones Exteriores entre el 9 de julio y el 28 de octubre de $1935^{4}$ antes de ser enviado a Europa para cubrir una "misión confidencial" en la representación plenipotenciaria de México

Luis G. Zorrilla. Relaciones de México con la Repuiblica de Centro América y con Gllalemala. México. Porrúa, 1984 (Biblioteca Porrúa, núm. 82), p. 186.

2 Ihid. p. 187-188.

Hid., p. 188 .

+ Secretarios y encargados del despacho de Relaciones Exteriores. México, Secretaria de Relaciones Exteriores, 1977, p. 22. 
ante su majestad británica, a la sazón encabezada por Miguel Santa Maria, y buscar en Roma que la Santa Sede reconociera la independencia de México.

A sólo un mes de haber llegado Díez de Bonilla a Roma, el 29 de noviembre de $1836,{ }^{5}$ el Vaticano reconoció oficialmente la independencia de México, a pesar de las gestiones en contrario realizadas desde México por el obispo de Puebla, Francisco Pablo Vázquez, ${ }^{6}$ quien habia estado en Roma en calidad de enviado extraordinario y ministro plenipotenciario, precisamente en aras del mismo fin, entre 1825 y 1831 .

Un largo receso en el quehacer internacional resultó de los gobiernos liberales y de otras actividades a que se dedicó Diez de Bonilla, hasta que sucedió a Lucas Alamán como secretario de Relaciones Exteriores, cuando ocurrió el fallecimiento de éste en junio de 1853, y permaneció como tal hasta que se derrumbó por última vez Su Alteza Serenísima, el general presidente Antonio López de Santa Anna, en agosto de 1855, y su escritorio pasó a ser ocupado efímeramente por Melchor Ocampo.'

Tres años y medio después habria de volver al puesto por casi cinco meses, entre febrero y julio de $1859,{ }^{8}$ durante el agitado interludio en que Miguel Miramón era uno de los dos presidentes de México; esto es, en circunstancias difíciles y de muy poca calma, a diferencia del bienio 53-55, en que tuvo en cierta medida más tiempo y posibilidad de desenvolver su calidad diplomática.

Entre otras cosas, a Diez de Bonilla tocó negociar con James Gadsen, el ministro plenipotenciario de los Estados Unidos en México, todo lo relacionado con el Tratado de La Mesilla, mismo que ambos firmaron el 30 de diciembre de 1863 .

Los documentos que se transcriben a continuación son tres casos seguidos de crónica mensual que, siendo secretario, envió firmados de su puño a cada uno de los pocos representantes que entonces tenía México en el exterior, con las instrucciones de que cada uno de ellos divulgara su contenido.

Se trata, sin duda, de la versión oficial por excelencia que daba de los hechos el gobierno ahora más execrado de López de Santa Anna, cuando, al decir de O'Gorman, se estableció en México una verdadera monarquía sin príncipe o, más bien, con presidente. No aportan, en efecto, estas reseñas información nueva alguna sobre los hechos a que se refieren, pero sí exhiben lo que de ellos opinaban los mandamases de entonces.

Como es de suponerse, estas reseñas no son las únicas que envió el secretario Diez de Bonilla; hay varias más en el Archivo Histórico Diplomático "Genaro Estrada" de la Secretaría de Relaciones Exteriores. Las que aqui se incluyen, ${ }^{9}$ correspondientes al primer dia de febrero, de marzo y de abril de 1854, fueron escogidas quizá un tanto al azar o porque los temas abordados son de gran

\footnotetext{
5 Joaquin Ramírez Cabañas, Las Relaciones entre Méxicó y el Vaticano, México, Secretaria de Relaciones Exteriores, 1928 (Col. Archivo Histórico Diplomático Mexicano núm. 27).

- Luis Medina Ascensio, Mérico y' el Vaticano. La iglesia y el estado liberal, 1836-1867, t. II, México, Jus, 1984, p. 67.

7 Secretarios y encargados..., op. cit., p. 44.

* Ibid., p. 52.

${ }^{9}$ Se encuentran en el legajo Fil. 8 (II).
} 
importancia para la historia mexicana, a saber: la rebelión de Juan Alvarez en el sur, las expediciones prácticas en el noroeste de Walker y Raousset, el tratado con Gadsen, la muerte de Nicolás Bravo, etcétera.

\section{MÉXICO, MARZO 3 de 1854}

Merced al empeño con que, tanto el supremo gobierno como todas las autoridades, vigilan por conservar la paz y el orden en la República. se habia interceptado una correspondencia por la que se descubrieron los planes traidores del Conde de Raousset. Debido a ese mismo celo el supremo gobierno ha descubierto que algunos malos mexicanos, expulsados de la República por sus tendencias revolucionarias y anárquicas, se han reunido en Nueva Orleáns y desde aquel punto tratan de seducir a algunas personas para hacerlas instrumentos de sus miras ambiciosas, habiendo llegado su maldad hasta el extremo de querer ponerse de acuerdo con el infame Raousset para hacer un movimiento combinado que les proporcione el logro de sus deseos de codicia y de venganza, aunque sea a costa de la desmembración de la República y de la pérdida de su honor.

Para evitar tales tentativas, el supremo gobierno ha dictado las providencias más enérgicas y oportunas, y siendo una de éstas el establecimiento de cantones militares que, próximos a cualquiera de los puntos que puedan ser atacados, ocurran a ellos las tropas con la brevedad posible. ha hecho marchar un número considerable de fuerzas para cubrir el litoral del Pacífico, dirigiéndose una división a California al mando del general Blancarte, y otras por diversos puntos por el rumbo del sur, situándolas por ahora en Chilpancingo con el fin de estar inmediatas a Acapulco, cuyo fuerte se iba a fortificar para desde alli. por medio de vapores que el gobierno se ha procurado, poder comunicar las órdenes y auxilios convenientes a los demás puertos de la costa del Pacifico.

Estas medidas, sin embargo, han servido de pretexto a los revoltosos, a cuya cabeza está don Juan Alvarez, para propalar las especies más absurdas. pues pretende que la intención del gobierno es apoderarse de su persona por considerarlo un obstáculo a la realización de planes ridículos que le atribuyen; y con semejantes especies ha conseguido alucinar a los habitantes sencillos y rudos de aquel rumbo, que parece están destinados a servir de instrumentos ciegos a las pérfidas maquinaciones de ese hombre funesto, que tanta sangre ha hecho correr en aquellos paises de que se cree señor y de los que ha hecho el teatro de sus crimenes. Este mismo Alvarez, que hoy levanta el estandarte de la rebelión. llamando tirano y despótico al régimen actual que la nación se ha dado libre y espontáneamente, escribia hace poco tiempo en la parte expositiva del acta que levantó adhiriéndose al plan proclamado en Jalisco para prorrogar el tiempo que deben durar las amplias facultades de que su Su Alteza Serenisima se halla investido, que sólo sentía no ser él quien primero hubiese proclamado una idea que consideraba como la única que podia salvar al pais de su completa ruina. Esta horrible perfidia en el momento mismo que preparaba su rebelión y el ofrecimiento que ha hecho a los agentes en los Estados Unidos de que les cederá terrenos hasta la Sierra Gorda si llega a triunfar, por tal que le ministren recursos y armas, es un rasgo característico de su conducta, siempre desleal e inicua, pero en esta vez no quedará impune de su traición, pues Su Alteza Serenísima, que no puede tolerar que la autoridad que la nación le ha confiado, para que la haga respetar, sea objeto de burlas, está resuelto a castigar muy severamente a los trastornadores de la tranquilidad pública, para lo cual cuenta con los medios de hacer efectivas sus providencias. 
En la Alta California se siguen haciendo enganches y preparativos de agresión: pero además de las medidas adoptadas por el supremo gobierno para frustrar sus designios. el estado que guardan nuestras relaciones con los Estados Unidos es sumamente satisfactorio, a consecuencia del último tratado celebrado por el cual éstos han dado ya las órdenes más terminantes a sus buques de guerra en aquella estación para perseguir a los filibusteros que invadieron la Baja California, impedirles que reciban auxilios de sus cómplices y castigarlos por tan criminales expediciones, habiendo salido en consecuencia del puerto de San Diego la fragata "Portsmouth" y el vapor "Columbia" el 17 de enero próximo pasado, y es de esperar que Walker con su pandilla se hayan dispersado a la fecha.

El tratado celebrado con motivo de la cuestión dudosa suscitada por la posesión de La Mesilla era una necesidad para México si no queria entrar en una guerra con los Estados Unidos que, en las presentes circunstancias no hubiera sido posible hacer con probabilidades de buen éxito en los momentos mismos de reorganizar el pais, su hacienda pública, su ejército y dar fuerza y vigor a la autoridad pública. Por otra parte los arreglos hechos han sido bastante satisfactorios, pues por la cesión de una parte pequeña de terreno despoblado y en disputa y la derogación del artículo 11 del Tratado de Guadalupe, que en realidad era ilusorio porque se disputaba el sentido de él y se cuestionaba que a la sombra de dicho artículo hubiesen pretendido ejercer un protectorado muy perjudicial sobre aquella parte de la frontera, México recibirá en compensación veinte millones de pesos, suma que parecerá exorbitante comparada con la que recibió en 1848 por una parte considerablemente mayor y poblada de territorio, de los cuales cinco se destinarán a extinguir todas las reclamaciones de los ciudadanos americanos contra México, incluso la de la concesión de Garay que tanto ha dado que hacer en diversas épocas.

Dicho tratado fue sometido al Senado de los Estados Unidos con fecha 10 del próximo pasado, con ligeras modificaciones, que Su Alteza Serenisima ha aceptado, y es de esperar que muy pronto sea definitivamente aprobado, quedando asi restablecida la armonía con nuestros vecinos, asegurada la Baja California de las incursiones de los filibusteros y el gobierno con los medios suficientes para dedicarse a consolidar el orden establecido, organizar su hacienda pública y disciplinar un ejército que pueda ser su sostén y acabar con los restos de la demagogia que se ha refugiado en las insalubres costas del sur.

Por los diarios que acompaño a usted se impondrá de las medidas tomadas por los diversos ministerios a cuyo cargo están todos los ramos de la Administración, y por separado le remito los decretos relativos al acta de Navegación de la República; a la nacionalidad de las sociedades comerciales, que es complemento del de extranjería y nacionalidad de los habitantes de la República; el que declara conspiradores a los comerciantes que, en puertos sublevados, pidan efectos al exterior para importarlos por estos mismos; y por último el que prohibe que los cargamentos de los buques vengan consignados a los capitanes o sobrecargos de éstos. Separadamente recibirá usted instrucciones sobre el de clausura del puerto de Acapulco.

Su Alteza Serenísima previene a usted que a todas estas providencias les dé desde luego la debida publicidad para que produzcan sus efectos y que la omisión en hacerlo no ocasione reclamaciones en el particutar.

Bonilla

\section{MÉXICO, I" DE ABRIL DE 1854}

La rebelión de don Juan Alvarez, que participé a usted en mi reseña del mes anterior, está próxima a su fin. Ella no ha tenido eco en nin- 
gún otro punto de la República, pues de todas partes se reciben diariam:nte actas de adhesión al supremo gobierno redactadas en términos que manifiestan el horror que inspira ese ambicioso. Su Alteza Serenisima. que desde hace algún tiempo deseaba pasar algunos días en un clima más cálido para restablecer su salud, aprovechó esta circunstancia para marchar al rumbo del sur y dirigir por sí mismo la campaña. Con tal fin salió de esta capital el 16 del corriente acompañado del excelentisimo señor ministro de la Guerra y el 29 del pasado llegó a Chilpancingo. En todo el tránsito ha recibido Su Alteza Serenísima las más vivas demostraciones de entusiasmo de parte de aquellos pueblos que. oprimidos hace tanto tiempo por la tirania de Alvarez, lo llaman su libertador. En efecto lo es, pues su viaje no sólo tiene por objeto el extirpar para siempre los gérmenes de anarquía que se han abrigado en aquellas comarcas, creyéndose defendidos por un terreno escabroso y un clima mortifero, lo cual lo conseguirá muy pronto, sino que también lleva la mira-de conocer por sí mismo las necesidades de aquellos habitantes y proveer de remedio eficaz a sus males, sacándolos del estado casi bárbaro en que se encuentran.

Por lo demás, apenas comenzadas las operaciones militares el desaliento se ha apoderado ya de los secuaces de Alvarez, presentándose más de mil de ellos a las fuerzas del supremo gobierno acogiéndose a su clemencia. Varios capataces como Torres y Rodriguez han sido hechos prisioneros por las fuerzas avanzadas del gobierno y, juzgados militarmente, pagarán con la vida sus crímenes. Así es que Alvarez, seguido solamente de los que, identificados en sus maldades con él, no tienen otro arbitrio que correr su suerte, para evitarla se han refugiado en un cerro llamado del Peregrino y fortificándose en él. Sus fuerzas no llegan a ochocientos hombres, segün se dice, y es de creer que, abandonados y temidos de todos, tengan muy pronto que sucumbir y someterse al castigo que por tantos títulos merecen.

En la ciudad de Guanajuato se aprehendió a un individuo llamado don Mariano Cuesta, que fue denunciado como conspirador. En efecto, se le encontraron un pliego y algunos otros papeles; pero solamente resultaron complicadas otras dos personas, sin que su proyecto tuviese ramificación de ninguna clase. Inmediatamente fue sometido a un juicio con arreglo a la ley de conspiradores y hoy está la causa en revisión en el Supremo Tribunal de la Guerra.

La invasión de California ha concluido. Su jefe Mr. Walker, que se titula presidente, desocupó La Ensenada e intentó dirigirse, a la cabeza de cien filibusteros enfermos y extenuados, hacia Sonora; pero los más lo abandonaron y ha tenido que irse para San Diego acompañado de unos cuantos. Luego que salió, la corta fuerza de doce hombres que habia dejado para cuidar de sus heridos se desertó, teniendo el buque de guerra americano "Portsmouth", que estaba en la bahía bloqueándolos, que recoger a dichos heridos abandonados a su suerte. El segundo de Walker, Mr. Wathrius, fue arrestado en California y sometido a un juicio con arreglo a las leyes de aquel país; de manera que todas las llamadas autoridades de la Nueva Republica de Sonora y California, han desaparecido. Es igualmente satisfactorio decir a usted que. del mismo modo, ha terminado la expedición proyectada por el Conde de Raousset. Los aventureros que se habian alistado bajo su bandera, persuadidos de que iban a servir solamente de instrumento a las miras privadas de su jefe y conociendo los peligros a que se exponian, lo abandonaron completamente ofreciendo sus servicios al gobierno mexicano.

Este, para custodiar las costas del Pacífico, ha comprado dos vapores de guerra y situándolos en aquellos mares, y con esto y los refuerzos de esos mismos franceses presentados quedarán bien cubiertos nuestro litoral y frontera. 
La convención celebrada con el señor ministro de España sobre pago de créditos que tienen sus nacionales contra la República ha sido ratificada por su gobierno del mismo modo que lo fue por Su Alteza el presidente de esta República, con lo que quedó felizmente terminado este negocio.

El tratado de limites celebrado con Mr. Gadsen, enviado extraordinario y ministro plenipotenciario de los Estados Unidos, de que hablé a usted hace poco, parece que será aprobado por el Senado de aquella República.

Exceptuando el Departamento de Guerrero, la paz reina en toda la República, y, bajo su benéfica influencia, se promueven toda clase de mejoras materiales en lo que trabaja sin descanso el Ministerio de Fomento. que ha logrado establecer ya un colegio de agricultura práctica, otro de mineria y otro de industria. Los caminos han recibido también un adelanto considerable, pues desde la Independencia jamás se habían visto cuidados y repuestos con el esmero que hoy lo están por todas partes de la República. con especialidad el que va de esta capital a Veracruz por Orizaba, en el cual se ha concluido un puente magnífico llamado de la Soledad y todo se encuentra en el mejor estado.

La rapidez con que se ha extendido la apertura de pozos artesianos en este pais promete también resultados muy lisonjeros; pues terrenos inmensos que estaban abandonados por la escasez y aun falta absoluta de agua, quedarán con esta mejora capaces de ser cultivados y de aumentar considerablemente la riqueza agricola de México.

Por la colección de diarios que se remiten a usted verá los diversos decretos que se han expedido por las secretarias del Despacho y que todos ellos tienden a la consolidación del orden, arreglo de la Hacienda Pública y de la administración de justicia y la protección de las ciencias y las artes.

En el exterior se mantienen nuestras relaciones en el mejor estado, siendo cada vez más estrechos los vinculos con las naciones con quienes tenemos tratados y cuyos gobiernos manifiestan en sus comunicaciones toda la consideración y aprecio que ha sabido inspirarles la actual Administración. No es exagerado asegurar que jamás se había presentado una situación más lisonjera para el pais, ni un porvenir tan halagüeǹo.

Reitero a usted mi consideración.

Bonilla

\section{México, $1^{0}$ de mayo de 1854}

La expedición al sur de Su Alteza Serenisima el general presidente ha sido una continuación de triunfos: el día 13 del corriente obtuvieron las fuerzas que marchan a sus órdenes uno completo sobre la del faccioso Alvarez que, apoderada de los cerros llamados Coquillo y Peregrino, cuya posición militar es formidable, creyeron poder hacer frente a las mencionadas tropas; pero nuestros valientes soldados, despreciando todos los peligros en medio del fuego de los rebeldes y de innumerables peñas que éstos desprendian echándolas a rodar para entorpecer su marcha, se apoderaron a bayoneta de los fortines que defendian al citado cerro del Coquillo y pusieron a los rebeldes en vergonzosa fuga. Los que guardaban el Peregrino acobardados con la derrota de sus compañeros, huyeron tambièn despavoridos, abandonando sus armas y municiones y dejando en poder de nuestras tropas un número considerable de prisioneros. El cabecilla Alvarez, cobarde y pérfido como siempre, se había puesto a salvo anticipadamente dirigiéndose a Acapulco. Su Alteza Serenisima mandó una brigada de caballeria en persecución de los fugitivos $\mathrm{y}$, habiendo logrado alcanzarlos 
el dia 15 en el punto llamado Dos Arroyos, los atacaron y derrotaron completamente.

El mismo día fue destruida en Chamistlahuacan la gavilla de J. Abarca, compuesta de 300 hombres que, entregándose a toda clase de excesos, estaba asolando el Distrito de Chilapa. Este cabecilla quedó muerto en la acción y su cabeza puesta en una pica se colocó en el pueblo de Ayahualotla, de donde era nativo, para escarmiento de los traidores.

Su Alteza Serenísima el general presidente continúa su marcha para Acapulco y, según un oficio del señor gobernador del estado de Guerrero. de fecha 27 , se encuentra ya en aquella plaza dirigiendo personalmente las opèraciones militares contra el Castillo en donde por último se han refugiado los rebeldes. Es de creerse que a esta fecha se haya apoderado Su Alteza de la fortaleza expresada y concluido de este modo la rebelión del sur.

Antes de saberse en el interior la doble derrota de los facciosos del sur, el capitán don Vicente Vega trató de secundar el plan de Alvarez pronunciándose por él el 17 del corriente en la hacienda de Santa Teresa, jurisdicción de Rio Verde; pero inmediatamente que supieron su atentado los excelentísimos señores gobernadores de Querétaro, Guanajuato y San Luis Potosí, enviaron simultáneamente sobre él fuerzas más que suficientes para la destrucción de su gavilla, pero antes de que éstas llegaran el coronel Ruiz, a la cabeza de sólo 40 hombres, habia deshecho completamente la chusma de Vega, no quedando a éste más recurso que refugiarse en la sierra, en donde es perseguido por fuerzas considerables, y de un momento a otro se espera la noticia de su aprehensión.

En el estado de Michoacán había sido secundada la rebelión de Alvarez por su digno compañero Gordiano Guzmán; pero habiendo sido entregado por sus mismos secuaces que se pasaron al supremo gobierno, fue pasado por las armas con arreglo a la ley, con lo cual terminó ese motin y aquel estado continúa en la mayor tranquilidad, lo mismo que todo el resto de la República.

Con el mayor pesar participo a usted el fallecimiento del excelentísimo señor Benemérito de la Patria, general de división don Nicolás Bravo, acaecida en la ciudad que lleva su nombre, el día 22 del pasado. Los eminentes servicios que en todas las épocas de su vida prestó a la Patria este distinguidisimo mexicano, que fue uno de los primeros caudillos de nuestra independencia, su carácter recto, firme y caballeroso, lo elevaron a los primeros puestos del Estado, que desempeñó siempre con dignidad y decoro. En él ha perdido México uno de sus hijos más ilustres y la Administración actual un leal amigo y cooperador.

La expedición sobre la Baja California se dispersó, según participé a usted, pero su jefe Walker, que permanece aislado en Santo Tomás, habiendo perdido toda esperanza de triunfo, reunió unos 20 habitantes indefensos de aquel lugar y les exigió por la fuerza que declarasen su voluntad de formar una nueva República independiente eligiéndolo a él por jefe. El objeto de esta nueva perfidia era presentarse como una República de hecho a los Estados Unidos, pidiéndole su reconocimiento y protección para anexarse enseguida; mas esos mismos individuos han protestado contra ese acto de violencia luego que se vieron libres, y el gobierno general lo ha hecho también ante el de Washington para que en ningún tiempo pueda servir ese nuevo atentado de pretexto para desmembrar el territorio de la República.

Por lo demás, luego que regrese a la capital Su Alteza Serenísima se tomarán las medidas convenientes para que el infame Walker sea aprehendido y sufra el castigo de sus crimenes.

Todo el resto de la República disfruta de la más completa tranquilidad y por los periódicos que se remiten a usted verá las actas de adhe- 
sión que se reciben diariamente hasta de los pueblos más cortos de ella, lo cual manifiesta el aprecio y confianza general que la nación tiene en su actual gobierno.

Dé usted la publicidad conveniente a estas noticias y admita las seguridades de mi consideración.

Bonilla 